\title{
Kahramanmaraş Koşullarına Uygun Silajlık Mısır (Zea mays L.) Çeşitlerinin Belirlenmesi
}

\author{
Mehmet Fatih YILMAZ \\ Nedim ACAR ${ }^{2}$ \\ Rukiye KARA ${ }^{1}$
${ }^{1}$ Doğu Akdeniz Geçit Kuşağı Tarımsal Araştırma Enstitüsü Müdürlüğü, Onikişubat/KAHRAMANMARAŞ
${ }^{2}$ Ege Tarımsal Araştırma Enstitüsü Müdürlüğü, Mememen/IZZMIR
$\bowtie$ : mehmetfyilmaz@hotmail.com

Geliş (Received): 02.11.2017

Kabul (Accepted): 15.12.2017

\begin{abstract}
ÖZET: Bu araştırma, Kahramanmaraş koşullarına uygun ve yüksek verimli silajlık mısır çeşitlerinin belirlenmesi amacıyla, Doğu Akdeniz Geçit Kuşağı Tarımsal Araştırma Enstitüsü deneme alanında, 2014-2015 yıllarında 2 yıl süreyle yürütülmüştür. Deneme, mısır ıslah projesi yürüten tarımsal araştırma enstitülerinin kendi hatlarıyla elde ettiği melez (ADA) veya ortak melezlerden elde edilen (SASA) 5 adet F1 hibrid misır genotipi ve 4 kontrol çeşidi ile tesadüf blokları deneme desenine göre 3 tekerrürlü olarak kurulmuştur. Araştırmada incelenen özellikler; tepe püskülü gösterme süresi, bitki boyu, koçan/bitki oranı, yaprak/sap oranı, yeşil bitki verimidir. Yeşil bitki verimi bakımından genotip ortalamaları arasındaki farklılık önemli bulunmuş ve iki yılın ortalamasına göre sırasıyla Burak (8269 kg da-1), SASA 5 (7860 kg da-1), P.31Y43 (7596 kg da-1) en yüksek yeşil bitki verimlerine sahip olmuşlardır. Anahtar kelimeler: Genotip, koçan, bitki boyu, hibrid, yeşil bitki verimi.
\end{abstract}

\section{Determine Corn (Zea mays L.) Varieties Suitable for Kahramanmaraş Conditions}

\begin{abstract}
This research was carried out for two years in 2014-2015 at the trial area of East Mediterranean Transitional Zone Agricultural Research Institute in order to determine and high yield corn varieties suitable for Kahramanmaraş conditions. Experiments were carried out in three replicates according to randomized block design with 5 hybrid corn (ADA) or common hybrid (SASA) F1 hybrid corn genotype and 4 control types obtained by agricultural research institutes performing corn breeding project in their own lines. Features investigated in the research; tasseling time, plant height, cobs/plant rate, leaf/stem rate and green herb yield were determined. The difference between the genotype averages in terms of green plant yield was found to be significant and according to the two year average results Burak (8269 $\left.\mathrm{kg} \mathrm{da}^{-1}\right)$, SASA $5\left(7860 \mathrm{~kg} \mathrm{da}^{-1}\right)$, P.31Y43 (7596 kg da $\left.{ }^{-1}\right)$ had the highest green plant yields.
\end{abstract}

Keywords: Cultivars, cob, plant height, hybrid, green plant yield.

\section{Gİiș}

Bir işletmede karlılığ faktörler girdi fiyatlarını azaltmak ve ürün miktarını arttırmaktır. Ülkemiz hayvancılığının üretim girdileri, özellikle yem giderleri son derece yüksektir. Ayrıca hayvan varlığı yüksek olmasına karşılık kaliteli kaba yem açığı fazladır. Kaba yemler, çiftlik hayvanlarına yeşil olarak, kurutularak ve silaj yapılarak yedirilen bitkisel kökenli materyallerdir (Bahtiyarca ve Cufadar 2003). Çiftçilerimiz kaba yem sıkıntısının yaşandığı dönemlerde ve özellikle çayır-meralarda otlatma imkânının olmadığı kış aylarında hayvanlarını zorunlu olarak, besin maddesi içeriği çok düşük olan tahıl samanı ile beslemektedirler. Türkiye'de kaliteli kaba yem ihtiyacının karşılanması için tarla bitkileri ekiliş alanları içinde yem bitkileri üretim miktarının arttırılması gerekmektedir.

Mısır sahip olduğu zengin besin maddeleri nedeniyle doğrudan gida olarak insan ve hayvan beslenmesinde kullanıldığı gibi endüstri hammaddesi amacıyla da değerlendirilebilen kullanım alanları oldukça geniş olan önemli bir sıcak iklim tahılıdır. Misır, hayvan beslenmesinde kesif yem rasyonlarına katılarak kullanıldığı gibi gerek yeşil olarak, gerekse silaj olarak yem zincirinde, en önemli kaba sulu yemlerden biridir. Silaj besin maddelerindeki değer kayılarını en aza indiren, su içeriği yüksek kaba yem özelliği ile tarımı ileri ülkelerde yoğun olarak kullanılmaktadır (Kılıç 1997). Kaliteli bir yemin besleme değeri ve hazmolunabilir besin maddeleri içeriği yüksek, lignin ve lif içeriği ise düşüktür. Silaj kalitesini etkileyen diğer önemli bir faktör de silajda bulunan tane miktarıdır. En kaliteli silaj, koçanlarında \% 25-30 hatta daha fazla tane bulunan bitkilerden elde edilmektedir. Sindirilme oranının ve birim alandan alınan verimin yüksek olması sebebiyle misır, tüm dünyada mükemmel bir silaj bitkisi olarak kabul edilmektedir (Açıkgöz 1995). Mısır, herhangi bir katkı maddesine gereksinim duyulmadan silolanabilmesi nedeniyle hem dünyada hem de ülkemizde silajlık olarak en fazla tercih edilen bitkilerin başında gelmektedir (Açıkgöz ve ark., 2002).

Tarımda verimi arttırmanın başlıca yollarından biri, yüksek verimli çeşitleri geliştirmek ve kültürel önlemlerle bitkinin genetik potansiyelinden en yüksek derecede faydalanmaktır. Ülkemizde potansiyel tarım alanlarının son sınırına ulașılmıș olması nedeniyle, ekim alanlarını genişleterek üretimi arttırma imkânı sınırlanmıştır. $\mathrm{Bu}$ nedenle üretim genellikle, birim alandan alınabilecek verimi en yüksek seviyeye çıkarmakla mümkün olabilmektedir (Konuşkan, 2000). Diğer bitkilerde olduğu gibi mısır üretiminde yüksek verim elde edilebilmesi ancak ekolojilere uygun çeşitlerin yetiştirilmesi ile mümkün olup, her çeşit tüm ekolojilerde aynı performansı gösteremediğinden her 
yörenin kendi ekolojisine uyumlu çeşitlerin yerel denemelerle belirlenmesi gerekmektedir (Kapar ve Öz, 2006). Mısır çeşitleri arasında da verim ve silaj kalitesi bakımından önemli farklılıklar bulunmaktadır. Bu nedenle bölgelere uygun misır çeşitlerinin seçimi önemlidir. Açıkgöz ve ark. (2002), mısır, yüksek enerji verimi, ekimden hasada kadar makineli tarıma uygun olması, saklama ve kullanım kolaylığı, kayıp oranının az olması, yüksek kuru madde içermesi, sindirilme oranının yüksekliği, kaliteli ve lezzetli bir silaj yemi olması, birim alandan yüksek verim alınabilmesi, tohumluğunun kolay bulunması, herhangi bir katkı maddesine gereksinim duyulmadan silolanabilmesi nedeniyle hem dünyada hem de ülkemizde silajlık olarak en fazla tercih edilen bitkilerin başında yer aldığını bildirmiştir. Erdal ve ark., (2009), bazı silajlık mısır çeşit adaylarının silajlık verim ve kalite özelliklerinin belirlenmesi amacıyla 2006 yılında 8 adet tek melez, 2007 yılında 7 adet tek melez ve 1 adet sentetik çeşit adayı ile Antalya koşullarında yürüttükleri çalışmada 2006 yılında bitki boylarının 226-250 cm, yaprak/sap oranlarının \% 41.3-52.3, koçan/bitki oranlarının \% 29-40, \% 50 çiçeklenme gün sayılarının 59-66 gün, yeşil ot verimlerinin $\mathrm{kg} \mathrm{da}^{-1}$ arasında, 2007 yılında ise bitki boylarının 241-303 cm, yaprak/sap oranlarının \% 41.6-58.3, koçan/bitki oranlarının \% 26.640, \% 50 çiçeklenme gün sayılarının 58-65 gün, yeşil ot verimlerinin $5461-7654 \mathrm{~kg} \quad \mathrm{da}^{-1}$ arasında değişim gösterdiğini bildirmişlerdir. Kuşaksız (2011), Manisa ekolojik koşullarında ana ürün silajlık olarak uygun mısır çeşitlerinin belirlenmesi amacıyla 2006 yılında 15 çeşitle yürüttüğü çalışmada bitki boylarının 166.8-240.1 $\mathrm{cm}$, koçan oranlarını \% 22.01-33.45, yaprak oranlarının $\%$ 22.57-29.75, sap oranlarının \% 40.08-52.01, yeşil ot verimlerinin $3774.30-8494.56 \mathrm{~kg} \mathrm{da}^{-1}$ arasında değişim gösterdiğini bildirmiştir. Öner ve ark. (2011), bazı silajlık mısır çeşitlerinde verim ve kalite özelliklerinin belirlenmesi amacıyla 2010 yılında Samsun-Çarşamba koşullarında 7 misır çeşidiyle yürüttükleri çalışmada bitki boylarının 301-330 cm, yeşil ot verimlerinin 6075$7391 \mathrm{~kg} \mathrm{da}^{-1}, \% 50$ çiçeklenme gün sayılarının 58-65 gün, yaprak/sap oranlarının \% 26-43, koçan bitki oranlarının \% 33-41 arasında değişim gösterdiğini bildirmişlerdir. Balmuk (2012), Konya-Yunak koşullarında ikinci ürün olarak yetiştirilebilecek silajlık misır çeşitlerinin verim ve verim özelliklerinin belirlenmesi amaciyla 2010 y1lı vejetasyon döneminde 13 çeşitle yürüttüğü çalışmada bitki boylarının 209.7$274.17 \mathrm{~cm}$, tepe püskülü çıkarma sürelerinin 60-68 gün, yeşil ot verimlerinin $3576.2-5047.6 \mathrm{~kg} \mathrm{da}^{-1}$ arasında değişim gösterdiğini bildirmiştir. Kabakçı (2014), Iğdır ekolojik şartlarına uygun silajlık misır çeşitlerinin belirlenmesi amacıyla 2013 yılında Iğdır'da 9 çeşitle yürüttüğü çalışmada bitki boylarının 256-319 cm, yeşil ot verimlerinin $4673.7-8753.7 \mathrm{~kg} \mathrm{da}^{-1}$, tepe püskülü çıkarma sürelerinin 64.7-76.7 gün, koçan/bitki oranlarının \% 24.6-38.3 arasında değişim gösterdiğini bildirmiştir. Han (2016), Giresun İli Bulancak İlçesi ekolojik koşullarında bazı mısır çeşitlerinin dane verimleri ile silaj ve kalite özelliklerinin belirlenmesi amacıyla 2015 yılında yapılan bu çalışmada, bitki boyu 286.7-315.6 cm, yaprak/sap oranı \% 36.8-47.4, yeşil ot verimi $7270-8441 \mathrm{~kg} \mathrm{da}^{-1}$, tepe püskülü çıkarma süresi 63.6-68.3 gün, koçan/ bitki oranı \% 27.4-35 arasında değişmiştir. Çeşitler arasında dane verimi bakımından istatistiksel açıdan fark önemli, yeşil ot verimi bakımından önemsiz bulunmuştur.

$\mathrm{Bu}$ araştırmada mısırın ekim alanı ve üretim bakımından ekonomik öneme sahip olan Kahramanmaraş ilimiz ekolojik koşullarına uygun ve yüksek verimli silajlık mısır çeşitlerinin belirlenmesi amaçlanmıştır.

\section{MATERYAL Ve YÖNTEM}

Bu çalışmada, Ülkesel Mısır Entegre Ürün Yönetimi Projesi çerçevesinde mısır ıslahı araştırması yapan tarımsal araştırma enstitülerinin elde ettiği ve ortak melez misır hibrid çeşit adayı 5 adet genotip (ADA12.40,ADA12.44, SASA-5, SASA-73, SASA-88) ve 4 adet kontrol çeşidi (BURAK, KILOWATT, P31Y43, SAMADA-07) materyal olarak kullanılmıştır. Çalışma mısır genotipinin ana ürün olarak Kahramanmaraş koşullarındaki performanslarını belirlemek amaciyla, 2014 ve 2015 yıllarında Doğu Akdeniz Geçit Kuşağı Tarımsal Araştırma Enstitüsü Müdürlüğü deneme alanında yürütülmüştür. Denemenin yürütüldüğü alan, akarsularca taşınmış alüviyal topraklar olup, etkili toprak derinliği fazla, drenajı iyi, tınlı bünyeye sahip eğimi düze yakın, birinci sınıf tarım arazisidir. Organik maddece fakir, tuzluluğu önemsiz fakat kireç oranı (\% 21.45) yüksek olup, pH's1 8.0 olup orta alkali bir özellik göstermektedir. Azotça fakir, potasyum miktarı bakımından ise zengindir. Fosfor yeterli miktarda bulunmaktadır. Kahramanmaraş İli Ülkemizin Güneydoğusunda $27^{\circ} 11^{\prime}$ - $38^{\circ} 36^{\prime}$ Kuzey paralelleri ve $36^{\circ} 15^{\prime}-37^{\circ} 41^{\prime}$ Doğu meridyenleri arasında yer almakta ve $568 \mathrm{~m}$ rakıma sahiptir. Yazları sıcak ve kurak kışları ılık ve yağışı bir Akdeniz iklim özelliği göstermektedir. Her iki yılda da yetiştirme süresi boyunca deneme sonucunu etkileyebilecek anormal iklim durumları gözlenmemiştir.

Toprak analizleri dikkate alınarak azotlu gübre toplamda üçe bölünerek verilmiștir. Yarayışlı fosfor ve potasyum miktarı yeterli olduğundan bu gübreler verilmemiştir. Toplam $25 \mathrm{~kg} \mathrm{da}^{-1} \mathrm{~N}$ gübrelemesi yapılmıştır. Deneme yeşil ot hasadına kadar deneme beş defa sulanmıştır.

Deneme tesadüf blokları deneme desenine göre 3 tekerrürlü olarak kurulmuştur. $5 \mathrm{~m}$ uzunluğundaki her parsel sıra arası mesafe $70 \mathrm{~cm}$ olacak şekilde 3 sıradan oluşmuştur. Parsel alanı $5 \mathrm{~m} \mathrm{x} 3$ sıra x $0.7 \mathrm{~m}=14 \mathrm{~m}^{2}$ 'dir. Sıra üzeri $15 \mathrm{~cm}$ olacak şekilde elle ekim yapılmıştır. Bitkilerin \% 50’ sinin, ekim tarihinden itibaren tepe püskülleri salkımının 1/3 kısmında polen dökme tarihine kadar geçen süre gün olarak tepe püskülü gösterme süresi olarak alınmıştır. Her parselde tesadüfi olarak seçilen 10 bitki üzerinde ölçümler yapılarak; döllenme sonrası toprak yüzeyinden tepe püskülünün en uç noktasına kadar olan mesafe ölçülerek bitki boyu olarak alınmıştır. Her parselden 5 bitkinin 
koçan ağırlıkları ve bitki ağırlıkları tespit edilip oranlanarak koçan/bitki oranı, (koçan hariç) yaprak ve sap ağırlıkları tespit edilip oranlanarak yaprak/sap oranı belirlenmiştir. Hasat ortadaki iki sırada $\left(\begin{array}{lll}7 & \mathrm{~m}^{2}\end{array}\right)$ yapılmıştır. Birim alan yeşil bitki verimi hamur olum dönemine gelen, koçanda süt çizgisi $1 / 2$ durumunda olan bitkiler (\% 60-65 su) toprak seviyesinden $5-6 \mathrm{~cm}$ yükseklikten hasat edilip ağırlığı birim alan verime çevrilerek ( $\left.\mathrm{kg} \mathrm{da}{ }^{-1}\right)$ bulunur (Anonim, 2010). Elde edilen veriler varyans analizine tabi tutulmuştur. Ortalamaların karşılaştırılması için LSD değerleri hesaplanmıştır.

\section{BULGULAR ve TARTIŞMA}

2014-2015 yılları ile iki yılın birleştirilmesiyle oluşan ve incelenen özelliklere ait varyans analiz sonuçları, ortalama değerler ve AÖF (0.05) testine göre oluşan gruplar Çizelge 1. ve Çizelge 2'de verilmiştir.

Çizelge 1'de görüldügüü üzere iki yılın ortalaması bakımından tepe püskülü gösterme süresi çeşit $(\mathrm{P}<0.01)$ ve yıl $(\mathrm{P}<0.05)$ interaksiyonu istatistiki açıdan önemli iken, çeşit x yıl interaksiyonu önemsizdir. Genotiplerin erkencilik-geççilik özelliğinin tespit edilmesi amacıyla önemli olan tepe püskülü çıkarma süresi bakımından genel olarak genotip ortalamaları 65-68 gün arasında değerler aldığı görülmektedir. SASA-73genotipi en kısa sürede tepe püskülü gösterirken, ADA12.20 ve SASA-5 genotipleri en uzun sürede tepe püskülü göstermişlerdir.
Tepe püskülü gösterme süresinin; Erdal ve ark. (2009) 58-65 gün, Öner ve ark. (2011) 58-65 gün, Balmuk (2012) 60-68 gün, Han (2016) 66.6-70.3 gün arasında değiştiğini bildirmişlerdir. Misırda tepe ve koçan püskülü çıkarma suresi, genotip ve çevre faktörlerinden etkilenmekte olup, nemli ve serin havalarda çiçeklenme süresi uzamakta, sıcak havalarda ise kısalmaktadır (Kün ve Emeklier, 1987).

Çizelge 1 incelendiğinde iki yılın ortalamasında çeşit interaksiyonunun bitki boyu üzerine istatistiki açıdan $\mathrm{P}<0.01$ düzeyinde önemli etkide bulunduğu, yıl ve çeşit $\mathrm{x}$ yıl interaksiyonunun ise istatistiki açıdan önemsiz etkide bulunduğu saptanır. Denemede kullanılan materyallerin en uzun $299 \mathrm{~cm}$ (SASA-5) ve en k1sa $246 \mathrm{~cm}$ (ADA 12.20) ortalama boy değerleri aldığ 1 tespit edilmiştir. Bitki boyları ortalamasının Erdal ve ark. (2009) 241-303 cm, Öner ve ark. (2011) 301-330 $\mathrm{cm}$, Balmuk (2012) 209.7-274.17 cm, Han (2016) 286.7-315.6 cm arasında değiştiğini bildirmişlerdir. Denemeden elde edilen bitki boyu sonuçları ile diğer araştırıcıların sonuçları arasında gözlenen farklar genetik yap1, çevre faktörleri ve uygulanan teknikkültürel uygulama farklılıklarından kaynaklandığı söylenebilir. Silajlık mısır yetiştiriciliğinde amaç birim alandan daha fazla yeşil aksam elde etmektir. Bu nedenle diğer özelliklerle birlikte yüksek bitki boyu önem arz etmektedir.

Çizelge 1. Y1llara göre tepe püskülü gösterme süresi, bitki boyuna ait ortalama değerler ve AÖF (\% 5) testine göre oluşan gruplar

\begin{tabular}{|c|c|c|c|c|c|c|}
\hline \multirow[t]{2}{*}{ Genotipler } & \multicolumn{3}{|c|}{$\begin{array}{l}\text { Tepe Püskülü Gösterme Süresi } \\
\text { (gün) }\end{array}$} & \multicolumn{3}{|c|}{$\begin{array}{l}\text { Bitki Boyu } \\
(\mathrm{cm})\end{array}$} \\
\hline & 2014 & 2015 & Ortalama & 2014 & 2015 & Ortalama \\
\hline ADA 12.20 & $68 \mathrm{a}$ & $67 \mathrm{~b}$ & $68 \mathrm{a}$ & $246 \mathrm{e}$ & $245 \mathrm{~d}$ & $246 \mathrm{~g}$ \\
\hline ADA 12.44 & $66 \mathrm{ab}$ & $67 \mathrm{bc}$ & 66 b-e & $249 \mathrm{e}$ & $267 \mathrm{c}$ & 258 ef \\
\hline SASA-5 & $66 \mathrm{ab}$ & $69 \mathrm{a}$ & $68 \mathrm{ab}$ & 297 a & $300 \mathrm{a}$ & 299 a \\
\hline SASA-73 & $65 \mathrm{~b}$ & $65 \mathrm{~d}$ & $65 \mathrm{e}$ & 269 b-d & $270 \mathrm{bc}$ & $270 \mathrm{~cd}$ \\
\hline SASA-88 & $65 \mathrm{~b}$ & $67 \mathrm{bc}$ & $66 \mathrm{c}-\mathrm{e}$ & 271 bc & $284 \mathrm{ab}$ & $278 \mathrm{bc}$ \\
\hline BURAK & $67 \mathrm{ab}$ & $67 \mathrm{~b}$ & 67 a-c & $281 \mathrm{ab}$ & $285 \mathrm{ab}$ & $283 \mathrm{~b}$ \\
\hline KILOWATT & $65 \mathrm{~b}$ & $66 \mathrm{~cd}$ & $66 \mathrm{de}$ & 254 de & $246 \mathrm{~d}$ & $250 \mathrm{fg}$ \\
\hline P31Y43 & $66 \mathrm{ab}$ & $67 \mathrm{~b}$ & 67 a-d & 257 c-e & $274 \mathrm{bc}$ & $265 \mathrm{de}$ \\
\hline SAMADA-07 & $65 \mathrm{~b}$ & $66 \mathrm{~b}-\mathrm{d}$ & $66 \mathrm{de}$ & $266 \mathrm{~b}-\mathrm{d}$ & $250 \mathrm{~d}$ & 258 ef \\
\hline Ortalama & 66 & 67 & 66 & 266 & 269 & 267 \\
\hline AÖF (0.05) & 2.68 & 1.45 & 1.46 & 17.26 & 16.83 & 11.58 \\
\hline DK $(\%)$ & 2.35 & 1.26 & 1.87 & 3.76 & 3.61 & 3.68 \\
\hline Çeşit & ÖD & $* *$ & $* *$ & $* *$ & $* *$ & $* *$ \\
\hline Y1l & & & $*$ & & & ÖD \\
\hline Çeşit xYı1 & & & ÖD & & & ÖD \\
\hline
\end{tabular}

**: $\mathrm{P}<0.01$ olasılık düzeyinde önemli, *:P<0.05 olasılık düzeyinde önemli, ÖD: önemli değil.

Çizelge 2'de iki yılın ortalaması incelendiğinde koçan/bitki oranı bakımından çeşit ve yıl interaksiyonunun istatistikî açıdan $\mathrm{P}<0.01$ düzeyinde önemli, çeşit x yıl interaksiyonunun ise istatistikî açıdan önemsiz olduğu belirlenmiştir. İyi kalitede bir silaj için mısır bitkisinin koçan/bitki oranının fazla olması istenir. Çünkü silajlık mısırda yeşil aksam besleme değerinin \%70'i koçanlardan yani tanelerden sağlanmaktadır (Orak ve İptaş, 1999). Açıkgöz (2001)'de iri ve bol koçanlı çeşitlerin silaja daha uygun olduğunu bildirmiştir. Bu çalışmada KILOWAT (\% 44.17), ADA 12.44 (\% 44.02), SASA-88 (\% 43.37) en yüksek koçan/bitki oranına sahip genotipler olurken BURAK (\% 33.18) en düşük koçan oranına sahiptir. Erdal ve ark. (2009) \% 26.6-40, Öner ve ark. (2011) \% 33-41, Kuşaksız (2011) \% 22.01-33.45, Kabakcı (2014) 24.638.3, Han (2016) \% 27.4-35yaptıkları çalışma sonuçlarını bildirmişlerdir. Sonuçlar arasındaki farklılık 
kullanılan materyalin ve dolayısıyla genetik yapılarının farklı olmasından ve denemelerin farklı ekolojik koşullarda kurulmasından kaynaklandığı söylenebilir.

Silajlık mısırda yaprak, sap ve koçan oranının belli bir denge halinde olması kalite düzeyi yüksek ürün elde edilmesinde önemli rol oynamaktadır. Değişik araştırıcılar mısır sapında sindirebilirliği yüksek karbonhidrat depolandığını ve bu karbonhidrat içeriğinin ise silaj kalitesine olumlu etki yaptığını tespit etmişlerdir (Cummins 1970; Schmid ve ark. 1976). Ancak misırda lignin ve selüloz gibi hayvanlar tarafından fazla tercih edilmeyen, aynı zamanda ürünün kalitesinin de azalmasına yol açan bileşikler saplarda yoğun bir şekilde bulunmaktadır. $\mathrm{Bu}$ nedenle iyi kalitede bir silajlık mısırda yaprak ve koçan oranının yüksek, sap oranının düşük düzeylerde olması istenir. Yaprak/sap oranı bakımından iki yılın ortalaması incelendiğinde istatistikî açıdan çeşit interaksiyonunun $\mathrm{P}<0.01$ düzeyinde önemli olduğu, yıl, çeşit $\mathrm{x}$ yıl interaksiyonunun ise önemsiz olduğu Çizelge 2.' den anlaşılmaktadır. İki yıllık denemelerin yaprak/sap oranı ortalaması incelendiğinde; genotip ortalamaları en yüksek (P31Y43) ve en düşük (BURAK) \%48.32-39.48 olarak görülmektedir. Erdal ve ark. (2009) \% 41.6-58.3, Öner ve ark. (2011) \% 26-43, Han (2016) \% 36.8-47.4 olarak bildirmiş olup denemelerden elde ettiğimiz yaprak/sap oranı sonuçlarına benzer sonuçlardır.

Çizelge 2'de görüldüğü üzere yeşil bitki verimi iki yılın ortalaması bakımdan çeşit $(\mathrm{P}<0.01)$ ve yıl $(\mathrm{P}<0.05)$ interaksiyonu istatistikî açıdan önemli, çeşit $\mathrm{x}$ yıl interaksiyonunun ise önemsizdir. İki yıllık yeşil bitki verimi ortalamaları incelendiğinde BURAK $(8269 \mathrm{~kg}$ $\mathrm{da}^{-1}$ ) standart çeşidi en yüksek verime sahipken, bunu sırasiyla SASA-5 genotipi (7860 kg da-1), P31Y43 $\left(7596 \mathrm{~kg} \mathrm{da}^{-1)}\right)$ standart çeşidi takip etmiştir. Erdal ve ark., (2009) 5461-7654 kg da ${ }^{-1}$, Öner ve ark., (2011) $6075-7391 \mathrm{~kg} \mathrm{da}^{-1}$, Balmuk, (2012) $3576.2-5047.6 \mathrm{~kg}$ $\mathrm{da}^{-1}$, Han, (2016) 7270-8441 kg da ${ }^{-1}$ yeşil bitki verimi elde ettiklerini bildirmişlerdir.

Çizelge 2. Yıllara göre koçan/bitki oranı, yaprak/sap oranı, yeşil bitki verimine ait ortalama değerler ve AÖF (\% 5) testine göre oluşan gruplar

\begin{tabular}{|c|c|c|c|c|c|c|c|c|c|c|c|c|c|}
\hline \multirow[t]{2}{*}{ Genotipler } & \multicolumn{3}{|c|}{$\begin{array}{c}\text { Koçan/Bitki Oranı } \\
(\%)\end{array}$} & \multicolumn{6}{|c|}{$\begin{array}{c}\text { Yaprak/Sap Oran1 } \\
(\%)\end{array}$} & \multicolumn{4}{|c|}{$\begin{array}{c}\text { Yeşil Bitki Verimi } \\
\text { (kg da-1) }\end{array}$} \\
\hline & 2014 & 2015 & Ortalama & 2014 & & 201 & & Ortala & & 2014 & & 2015 & Ortalama \\
\hline ADA 12.20 & $37.23 \mathrm{de}$ & $38.77 \mathrm{de}$ & $38.00 \mathrm{~cd}$ & 43.33 & $\mathrm{bc}$ & 45.33 & b-d & 44.33 & $\mathrm{~b}$ & 7290 & $a b$ & $6097 \mathrm{~cd}$ & 6694 bc \\
\hline ADA 12.44 & $44.87 \mathrm{a}$ & 43.17 a-c & $44.02 \mathrm{a}$ & 44.17 & $\mathrm{~b}$ & 46.40 & $\mathrm{bc}$ & 45.28 & $\mathrm{ab}$ & 7002 & $\mathrm{bc}$ & $6335 \mathrm{~cd}$ & 6669 bc \\
\hline SASA-5 & $32.67 \mathrm{f}$ & 36.77 ef & 34.72 ef & 44.17 & $\mathrm{~b}$ & 44.17 & b-e & 44.17 & $\mathrm{~b}$ & 7856 & $a b$ & $7863 \mathrm{ab}$ & $7860 \quad \mathrm{a}$ \\
\hline SASA-73 & $39.50 \mathrm{~cd}$ & 41.10 b-d & $40.30 \mathrm{bc}$ & 45.50 & $a b$ & 41.63 & de & 43.57 & $\mathrm{~b}$ & 5961 & $\mathrm{c}$ & $5974 \mathrm{~d}$ & $5967 \mathrm{c}$ \\
\hline SASA-88 & 42.67 a-c & $44.07 \mathrm{ab}$ & $43.37 \mathrm{a}$ & 49.87 & $\mathrm{a}$ & 43.50 & c-e & 46.68 & $a b$ & 6734 & $\mathrm{bc}$ & $6037 \mathrm{~d}$ & $6386 \mathrm{c}$ \\
\hline BURAK & $31.60 \mathrm{f}$ & $34.77 \mathrm{f}$ & $33.18 \mathrm{f}$ & 38.33 & $\mathrm{c}$ & 40.63 & $\mathrm{e}$ & 39.48 & $\mathrm{c}$ & 8452 & $\mathrm{a}$ & 8086 a & 8269 a \\
\hline KILOWATT & $43.60 \mathrm{ab}$ & $44.73 \mathrm{a}$ & $44.17 \mathrm{a}$ & 47.40 & $a b$ & 40.37 & $\mathrm{e}$ & 43.88 & $\mathrm{~b}$ & 6874 & $\mathrm{bc}$ & 6579 b-d & 6726 bc \\
\hline P31Y43 & 40.47 b-d & 43.27 a-c & $41.87 \mathrm{ab}$ & 44.97 & $a b$ & 51.67 & $\mathrm{a}$ & 48.32 & $\mathrm{a}$ & 7844 & $a b$ & 7348 a-c & 7596 a \\
\hline SAMADA-07 & 33.67 ef & 39.80 c-e & $36.73 \mathrm{de}$ & 45.67 & $a b$ & 47.83 & $a b$ & 46.75 & $\mathrm{ab}$ & 7793 & $a b$ & 7087 a-d & $7440 \mathrm{ab}$ \\
\hline Ortalama & 38.47 & 40.71 & 39.59 & 44.8 & & $44 .($ & & 44.7 & & 7312 & & 6823 & 7067 \\
\hline AÖF (0.05) & 3.95 & 3.61 & 2.57 & 5.54 & & 4.0 & & 3.28 & & 1180 & & 1306 & 846 \\
\hline $\mathrm{DK}(\%)$ & 5.93 & 5.12 & 5.52 & 7.14 & & 5.1 & & 6.24 & & 9.33 & & 11.06 & 10.18 \\
\hline Çeşit & $* *$ & $* *$ & $* *$ & $*$ & & $* *$ & & $* *$ & & $*$ & & $*$ & $* *$ \\
\hline Y1l & & & $* *$ & & & & & ÖD & & & & & $*$ \\
\hline Çeşit xY1l & & & ÖD & & & & & $* *$ & & & & & ÖD \\
\hline
\end{tabular}

**: $\mathrm{P}<0.01$ olasılık düzeyinde önemli, *:P<0.05 olasılık düzeyinde önemli, ÖD: önemli değil.

\section{SONUÇ}

Yeşil bitki verimi ortalamaları bazı standart çeşitlerin üzerinde çıkan SASA-5 genotipinin bölgemiz için ümitvar olduğu söylenebilir ve tescil olması halinde BURAK, P.31Y43 çeşitleriyle birlikte tavsiye edilebilir.

\section{TEŞEKKÜR}

Bu araştırma; Ülkesel Misır Entegre Ürün Yönetimi Projesi altında Kahramanmaraş koşullarında 2012-2016 yılları arasında 5 yıl süre ile yürütülen ve. T.C. Gıda, Tarım ve Hayvancılık Bakanlığı Tarımsal Araştırmalar ve Politikalar Genel Müdürlüğü tarafindan desteklenen Kahramanmaraş Koşullarına Uygun Tane ve Silajlık Misır Çeşitlerinin Belirlenmesi TAGEM/TBAD/12/A12/P03/02-001 kodlu projenin 2015-2016 yıllarındaki sonuçlarını kapsamaktadır. Doğu Akdeniz Geçit Kuşağı Tarımsal Araştırma Enstitüsü'nde görevli mesai arkadaşlarıma gönülden teşekkür ediyorum.

\section{KAYNAKLAR}

Açıkgöz E 1995. Yem Bitkileri (II. Baskı). Uludağ Üniversitesi Yayınları No: 7-025-0210, Bursa.

Açıkgöz E 2001. Yem Bitkileri. 3. Bask1, Uludağ Üniversitesi Güçlendirme Vakfi Yayın No. 182. VIP A.Ş. Yayın No:58, $584 \mathrm{~s}$, Bursa.

Açikgöz E, Turgut İ,. ve Filya İ 2002. Silaj Bitkileri Yetiştirme ve Silaj Yapımı. 86 s. Hasad Yayıncılık Ltd. Şti., ISBN 975-8377-19-1.

Anonim 2010. Tarımsal Değerleri Ölçme Denemeleri Teknik Talimatı. Tarım ve Köyişleri Bakanlığı, Tarımsal Üretim ve Geliştirme Genel Müdürlüğü, Tohumluk Tescil ve Sertifikasyon Merkezi Müdürlüğü, Ankara. 
Bahtiyarca Y, Çufadar Y 2003. Konya İli Yem Bitkileri Üretimi. Ulusal I. Konya Ekonomisi Sempozyumu, s. 401-409, Konya.

Balmuk Y 2012. Konya Yunak Koşullarında İkinci Ürün Olarak Yetiştirilebilecek Silajlık Misır Çeşitlerinin Verim ve Verim Özelliklerinin Belirlenmesi. Gazi Osmanpaşa Üniv. Fen Bilimleri Enstitüsü, Tokat, Yüksek Lisans Tezi.

Cummins D.G 1970. Quality and yield of corn plants and components parts when harvested for silage at different maturity stages. Agron J., 62: 781-784.

Erdal İ, Pamukçu M, Ekiz H, Soysal M, Savur O, ve Toros A 2009. Bazı Silajlık mısır çeşit adaylarının silajlık verim ve kalite özelliklerinin belirlenmesi. A.Ü. Ziraat Fakültesi Dergisi, 22(1): 75-81, Antalya.

Han E 2016. Bazı Mısır Çeşitlerinin Dane Verimleri ile Silaj ve Kalite Özelliklerinin Belirlenmesi, Ordu Üniversitesi Fen Bilimler Enstitüsü, Ordu, Yüksek Lisans Tezi.

Heath M.E, Bornes R.F, and Metcalfe D.S 1985. Forages. Iowa State Univ. Press. Forth ed., Ames, Iowa, USA.

Kabakci S 2014. Iğdır Ekolojik Şartlarına Uygun Silajlık Misır Çeşitlerinin Belirlenmesi. I.Ü. Fen Bilimleri Enstitüsü, Iğdır, Yüksek Lisans Tezi.

Kapar H, ve Öz A, 2006. Bazı mısır çeşitlerinin Orta Karadeniz Bölgesi'nde performanslarının belirlenmesi. Ondokuzmayis Üniversitesi Ziraat Fakültesi Dergisi, 21(2): 147-153.
Kılıç A 1997. Türkiye'de Kaba yem üretim ve yeterlilik düzeyi. Türkiye 1. Silaj Kongresi, Bursa, s. 11-18.

Konuşkan Ö 2000. Hatay Koşullarında İkinci Ürün Olarak Yetiştirilen Bazı Melez Mısır Çeşitlerinde Bitki Sıklığının Verim ve Verimle İlişkili Özelliklere Etkisi. Mustafa Kemal Üniv. Hatay, Yüksek Lisans Tezi, 189s.

Kuşaksiz T 2011. Manisa ekolojik koşullarında ana ürün silajlık olarak uygun mısır çeşitlerinin belirlenmesi. Türkiye 9. Tarla Bitkileri Kongresi s. 529-532, Bursa.

Kün E, ve Emeklier Y 1987. İklim faktörleri bakımından Türkiye'de misır üretiminin geliştirilmesi. Problemler ve Çözüm Yollar Sempozyumu, s. 1-9,Ankara.

Orak A, ve İptaş S 1999. Silo Yem Bitkileri ve Silaj. Çayır Mera Amenajmanı ve Islahı Tarım ve Köyişleri Bakanlığı Tarımsal Üretim ve Geliştirme Genel Müdürlüğü. s. 49-69. Ankara.

Öner F, Aydin İ, Sezer İ, Gülümser A, Özata E, ve Algan D 2011. Bazı silajlık mısır çeşitlerinde verim ve kalite özelliklerinin belirlenmesi. Türkiye 9. Tarla Bitkileri Kongresi s. 465-468, Bursa.

Schmid Ar, Goodrich R.D, Jordan R.M, Marten G.C, and Meiske Jc 1976. Relationships among Agronomic Characteristic of Corn and Sorghum Cultivars and Silage Quality Agron J., 68: 403-405.

Yılmaz İ 1999. Van koşullarında silajlık mısır yetiştirme olanakları üzerine bir araştırma. GAP I. Tarım Kongresi, 26-28 Mayıs 1999, s. 703-710, Şanlıurfa. 